Acta Biologica Plantarum Agriensis 5(1): 38 (2017) ISSN 2061-6716 (Print), 2063-6725 (Online)

http://abpa.ektf.hu/
DOI:10.21406/abpa.2017.5.1.38

$4^{\text {th }}$ CC 2017 Abstract

Lecture

\title{
MACROFUnGi FROM APUSENI MOUNTAINS, TRANSYLVANIA, ROMANIA
} Nagygombák az Erdélyi-szigethegységből

\author{
Kinga ORoss ${ }^{1}$, Lajos BENEDEK ${ }^{2}$ \&Ferenc PÁL-FÁM ${ }^{3}$
}

19062 Kisbajcs, Kossuth str. 40; ${ }^{2}$ Szent István University, Faculty of Horticultural Sciences, Department of Botany and Soroksár Botanical Garden; ${ }^{3}$ Kaposvár University, Institute of Plant Science; e-mail: oross.kinga@gmail.com

The Apuseni Mountains are one of the oldest mountains in the Carpathian Basin with medium-height character, but also with high plateau and peaks. However, from the mycological point of view it is less well studied. Present work's aim was to start a systematic mycological investigation, as well as to raise the mycologist's interest to this territory. The documented taxa were collected in August 2017 during a four day field trip by 30 participants. The investigated forest stands belong to mixed deciduousconiferous and spruce associations. A total number of 131 macrofungi taxa were documented during the 4 days. The functional distribution shows 69 (52,67\%) ectomycorrhizal, $32(24,43 \%)$ wood inhabiting saprotrophic, $18(13,74 \%)$ soil saprotrophic, 7 (5,34\%) necrotrophic parasite, 2 (1,53\%) moss-associated, 2 (1,53\%) coprotrophic and $1(0,76 \%)$ herbaceous saprotrophic species. Ascomycetes were represented by only two species, respectively Elaphomyces granulatus and Peziza badia. The richest genus was Russula with 16 species. Several common species were found, which are characteristic to the examined habitats, such as Amanita fulva, Amanita muscaria, Calocera viscosa, Cantharellus cibarius, Gloeophyllum sepiarium, Laccaria amethystina, Lactarius deterrimus, Lactarius turpis. Others, like Cortinarius caperatus and Lactarius rufus were the species characteristic to mountainous coniferous forests, while Cantharellus amethysteus, Climacocystis borealis, Pholiota flammans and Pseudohydnum gelatinosum were characteristic to mountainous spruce stands. Interesting species fructifying in the spruce stands were the saprotrophic Pleurocybella porrigens living on spruce trunks, and Xeromphalina campanella living on mossy conifer trunks. Among rare species Amanita submembranacea can be mentioned, which was fructifying in mountainous conifer stands with acidic soil, more rarely in acidic beech forests; Amanita battarrae was living in acidic deciduous and coniferous forests in the high mountains, as well as a species with typical colour, Gliophorus psittacinus, characteristic to grassy and mossy forest edges and clear forests. The Romanian Red List of Macrofungi contains the vulnerable (VU) Volvariella murinella and Phylloporus pelletieri, and the near threatened (NT) Amanita regalis and Lactarius picinus. Besides, it should be mentioned that Lactarius helvus, Russula decolorans and Russula paludosa are becoming rare because of their habitat retraction. Some species with indicative value were also documented, like Ischnoderma resinosum and Mucidula mucida in deciduous, Pluteus atromarginatus in coniferous stands, all of them indicating old, undisturbed forests. Besides, species indicating human disturbance were also collected, like Macrolepiota procera, Bovista plumbea and Inocybe rimosa. Further investigation of this territory is recommended, because the occurrence of several other interesting macrofungi is expected. That is why we plan to continue this investigation in close future. 